\title{
The influence of developmental diet on reproduction and metabolism in Drosophila
}

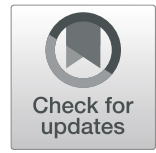

Peter Klepsatel ${ }^{1^{*}} \mathbb{D}$, Diana Knoblochová1,2, Thirnahalli Nagaraj Girish³, Heinrich Dircksen ${ }^{4}$ and Martina Gáliková ${ }^{1}$

\begin{abstract}
Background: The adaptive significance of phenotypic changes elicited by environmental conditions experienced early in life has long attracted attention in evolutionary biology. In this study, we used Drosophila melanogaster to test whether the developmental diet produces phenotypes better adapted to cope with similar nutritional conditions later in life. To discriminate among competing hypotheses on the underlying nature of developmental plasticity, we employed a full factorial design with several developmental and adult diets. Specifically, we examined the effects of early- and late-life diets (by varying their yeast and sugar contents) on reproductive fitness and on the amount of energy reserves (fat and glycogen) in two wild-caught populations.

Results: We found that individuals that had developed on either low-yeast or high-sugar diet showed decreased reproductive performance regardless of their adult nutritional environment. The lower reproductive fitness might be caused by smaller body size and reduced ovariole number. Overall, these results are consistent with the silver spoon concept, which posits that development in a suboptimal environment negatively affects fitness-associated traits. On the other hand, the higher amount of energy reserves (fat) in individuals that had developed in a suboptimal environment might represent either an adaptive response or a side-effect of compensatory feeding.

Conclusion: Our findings suggest that the observed differences in the adult physiology induced by early-life diet likely result from inevitable and general effects of nutrition on the development of reproductive and metabolic organs, rather than from adaptive mechanisms.
\end{abstract}

Keywords: Nutrition, Developmental plasticity, Environmental matching, Fecundity, Fat, Glycogen

\section{Background}

The environmental conditions experienced during development profoundly affect health and physiology in adult life. One of the critical factors determining adult fitness is developmental nutrition. The link between the prenatal diet and metabolic and heart diseases in later life has been demonstrated in diverse mammalian models. For example, restriction of nutrients during early development leads to an increased risk of obesity, type- 2 diabetes, and coronary heart diseases [1-3]. This effect is explained by the so-called thrifty phenotype hypothesis

\footnotetext{
* Correspondence: peter.klepsatel@gmail.com

'Institute of Zoology, Slovak Academy of Sciences, Dúbravská cesta 9, 84506 Bratislava, Slovakia

Full list of author information is available at the end of the article
}

$[4,5]$, which states that poor nutritional conditions during early development programs metabolism to cope with nutritional scarcity later in life. However, if the conditions improve during adulthood and food becomes more abundant, the adaptation to undernourishment becomes maladaptive, causing obesity, type- 2 diabetes, and related metabolic disorders. Not only undernutrition but also maternal/neonatal obesogenic (i.e. promoting excessive fat accumulation) environment results in long-term changes in energy metabolism and increases the incidence of metabolic diseases at a later age $[2,6]$. According to a more general concept of the predictive adaptive response (PAR) proposed by Gluckman and Hanson [7], adverse effects arise from a mismatch between earlyand late-life environments. The circumstances 
experienced during development may serve as clues for future environmental conditions, and trigger an adaptive response. Consequently, a match between developmental and adult environments increases individual fitness, whereas a mismatch can have negative impacts on survival and reproduction [8]. Predictive adaptive responses are instances of adaptive developmental plasticity [9]. According to theoretical studies [10, 11], the evolution of PARs might be expected only in organisms that live in very predictable environments.

Both the thrifty phenotype and PAR hypothesis can be categorised as an environmental matching model [12], which posits that in a given environment, individuals that developed in this environment have higher fitness than those that developed under different conditions; fitness is maximised when there is a match between developmental and adult environment [12]. An alternative explanation to the environmental matching model is the so-called silver spoon effect - favourable developmental conditions improve traits that are positively associated with adult fitness [13]. As a result, individuals that developed in a poor nutritional environment always have lower fitness than individuals reared under optimal conditions; both groups have higher fitness in resource-rich environments (reviewed in [12]). Monaghan [12] completed PAR and silver spoon concepts by implementing two new conceptual variations (models). In the first model, fitness is always higher in good conditions; however, individuals grown in poor conditions have better performance in a suboptimal environment than individuals that had developed under optimal conditions, i.e. developmental plasticity has adaptive character in this case. However, unlike the environmental matching model, fitness is not maximised by a match between developmental and adult environment. According to the second model, individuals that had developed under poor conditions always have lower fitness, which declines with increasing quality of an environment [12].

Over the past several decades, the fruit fly Drosophila melanogaster has become an excellent model organism for studying homeostatic regulation and metabolic disorders (e.g. [14]). Like in humans, obesity and diseases such as diabetes can be induced in flies by both dietary and genetic dysregulations (reviewed in [15]). Numerous studies in Drosophila have shown that early developmental diet has significant long-term consequences for adult physiology and various fitness-related traits such as lifespan, reproduction or stress tolerance. For example, flies reared on a low yeast diet have reduced body size (e.g. [16-18]), lower fecundity [17], but higher cold resistance [19]. In addition, a yeast-poor larval diet extends lifespan and increases the amount of fat reserves in adults $[20,21]$. Altogether, the composition of the developmental diet has far-reaching consequences for
Drosophila fitness. Nevertheless, there are only a few experimental studies in fruit flies [22, 23], which had tested the adaptive significance of phenotypic changes caused by the developmental diet in the context of adult nutritional environments. It is therefore still an open question, whether such changes represent adaptive responses to the given developmental diet, as suggested, for example, by the PAR hypothesis, or rather are inevitable consequences of development under sub-optimal conditions.

In this study, we used two wild-caught outbred populations of $D$. melanogaster to test to what extent does a match, or a mismatch between developmental and adult nutritional environment affect individual fitness. In order to distinguish among various hypotheses on the character of plasticity induced by early-life nutrition, we employed a full factorial design with all combinations of three developmental and adult diets that differed in the macronutrient composition [12]. We separately tested the impact of yeast (the principal source of protein and sterols for fruit flies [24-26]) and sugar concentration in Drosophila diet on two fitness-related traits. In Drosophila, diets with either reduced yeast or increased sugar content prolong development, reduce egg-to-adult survival, and decrease female fecundity e.g. [24, 27, 28]; these imbalanced diets can be therefore considered suboptimal. The first trait we examined is the early reproductive performance (fecundity and egg-to-adult viability). In a natural environment, Drosophila adults have a very short life expectancy (less than a week) [29]. Therefore, early reproductive performance represents a reliable proxy for reproductive fitness $[29,30]$. The second fitness-related trait we measured, the amount of energy reserves (fat and glycogen), plays an essential role in surviving periods of food shortage [31].

\section{Results \\ Effects of developmental diet on early reproductive fitness}

To avoid the adverse effect of inbreeding on life-history traits (e.g. [32, 33]) and to account for potential population differences, we examined individuals from two outbred, wild-caught populations of D. melanogaster originating from temperate (Slovakia) and tropical climatic region (India). First, we analysed the effect of developmental and adult diets and their interactions on early fecundity (Fig. 1). Since both dietary yeast and sugar have a significant influence on fitness-associated traits (e.g. [24]), we analysed the effects of yeast and sucrose separately, using low (2.5\%), intermediate (10\%) and high (25\%) concentrations of each compound.

Statistical analysis (multi-way ANOVA) of the effects of population origin ('population') and yeast concentration in the developmental and adult diet revealed that all these three factors, as well as their interactions (except 


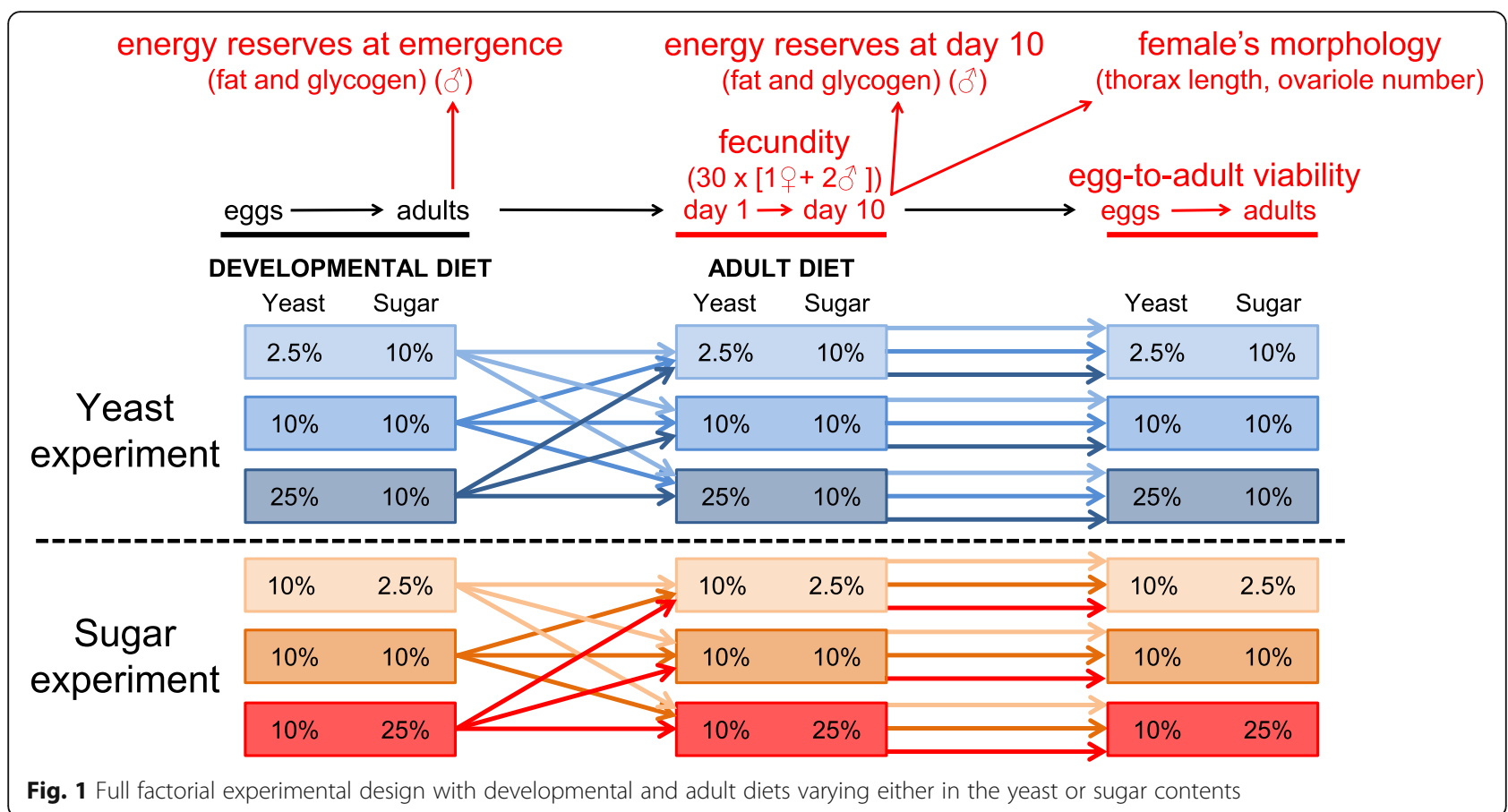

for 'population $\mathrm{x}$ developmental diet'), have significant impact on early fecundity (Additional file 1: Table S1). Similarly, the analysis of the effects of population and sugar content in the developmental and adult diet on early fecundity showed that all three factors and two of their interactions ('population $\mathrm{x}$ adult diet' and 'population $\mathrm{x}$ developmental diet') have a significant effect (Additional file 1: Table S2). In general, early fecundity was affected mainly by the adult diet; in comparison, the developmental diet had reduced importance, whereas population had only a minor effect. The dietary yeast and sugar had the opposite effect on reproductive output - while the early fecundity increased with the yeast content of the food, increased sugar concentration in the adult diet reduced the number of laid eggs.

Although there were some minor population differences, individuals from both populations that had developed on the low-yeast diet (2.5\% yeast) tended to lay (on average) fewer eggs on all three adult diets than individuals that had developed on either intermediate- or highyeast diet (Fig. 2). Similarly, the flies that had developed on the high-sugar diet had the lowest early fecundity regardless of the sugar concentration in the adult diet (Fig. 2). Interestingly, a match between developmental and adult diets tended to have a relatively positive effect on early fecundity in the case of diets with varied yeast contents; however, a similar effect was not detected for dietary sugar (Additional file 1: Tables S3 and S4).

Egg-to-adult viability was mainly unaffected by the developmental diet of parents; this trait was predominantly influenced by the medium on which the eggs were laid (Fig. 3; Additional file 1: Tables S1-S4).

Overall, we found that individuals that develop on either a low yeast or high sugar diet have reduced reproductive fitness independently of adult nutrition.

\section{Developmental diet and early fecundity standardised for body size and ovariole number}

Early fecundity strongly positively correlates with body size and the number of ovarioles, the functional units producing eggs (e.g. [30, 34-36]). Since the developmental diet can affect both these traits, we investigated, whether the observed effects of the developmental diet on reproductive performance depend on changes in body size and ovariole number.

As expected, the yeast and sugar content of the developmental diet had pronounced effects on both thorax length and ovariole number (Figs. 4 and 5; Additional file 1: Table S7). Flies from both populations that had developed on the intermediate- and high-yeast diet were significantly larger and had more ovarioles than the individuals that had developed on the low-yeast diet (Figs. 4 and 5). The sugar content of the developmental diet had exactly inverse effects; individuals that had developed on the high-sugar diet were smaller and with significantly fewer ovarioles (Figs. 4 and 5).

Next, we analysed to what extent the observed differences in early fecundity among the flies that had developed on different diets, are associated with variation in thorax length and ovariole number. We used two 


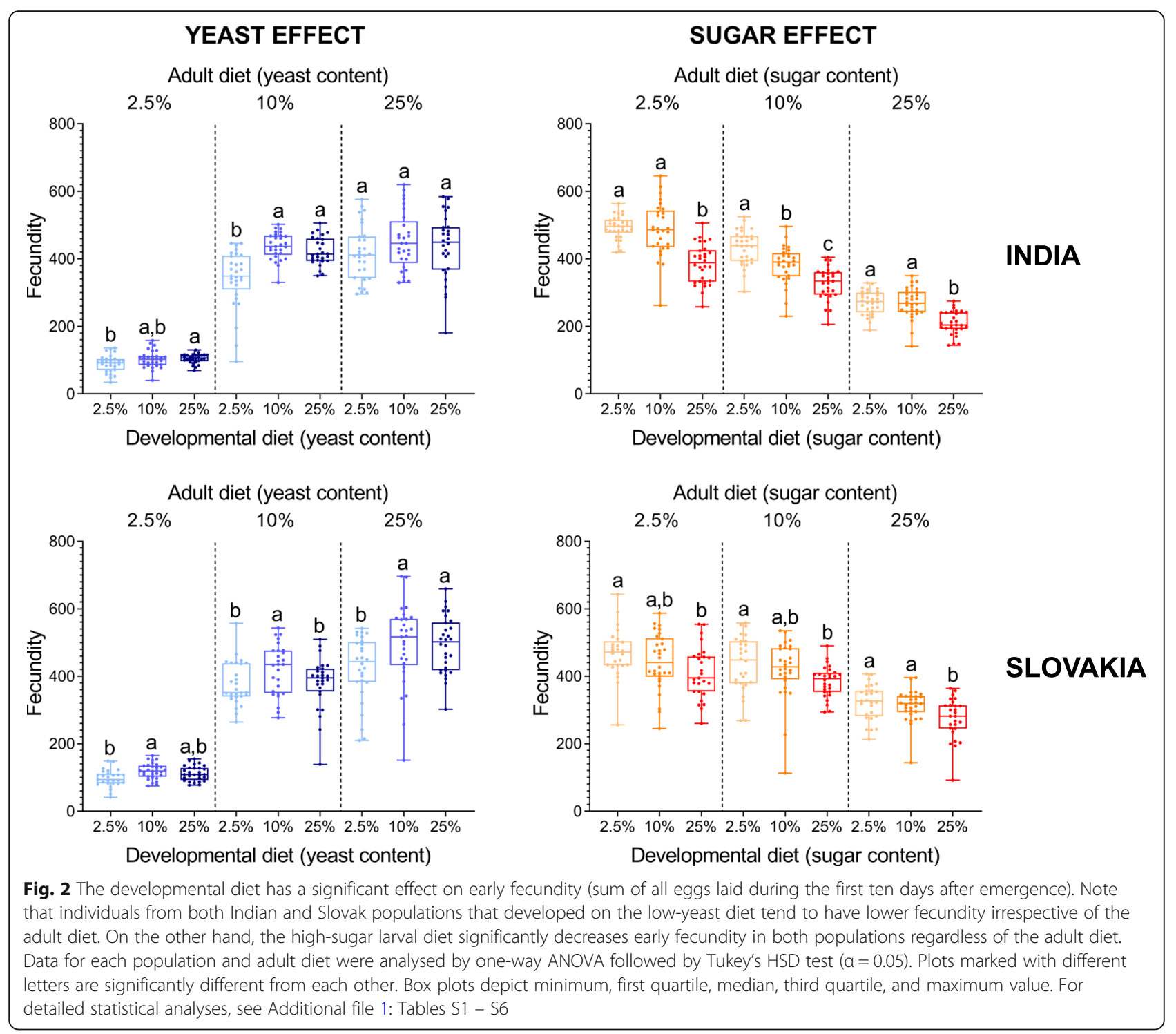

approaches: i) we standardised individual fecundity either by the body size (thorax length ${ }^{3}$ ) or ovariole number, and ii) we analysed fecundity by ANCOVA with either the thorax length or ovariole number as a covariate [37]. Importantly, both normalization methods provided similar results (Figs. 6 and 7; Additional file 1: Tables S8 and S9). When standardised for either body size or ovariole number, we detected only minor differences in the fecundity among flies that had developed on diets with varying amounts of yeast (Figs. 6 and 7). This might suggest that the significant differences in the reproductive performance can be explained by the diet-induced differences in body size and ovariole number. By contrast, although there were only minor differences in the fecundity standardised for either body size or ovariole number among the flies from Slovakia that had developed on diets with varied sugar contents, the negative impact of development on the high sugar diet on reproductive output was still observable in the population from India (Figs. 6 and 7). Overall, the fecundity standardised for either body size or ovariole number was affected primarily by adult diet. A match between developmental and adult diet did not seem to have a significant influence on these traits (Additional file 1: Tables S3 and S4).

In conclusion, we found that development on either lowyeast or high-sugar diet reduces body size and ovariole number, which might explain the observed lower reproductive fitness of individuals that developed on these diets.

\section{Effects of developmental diet on energy reserves}

Finally, we examined how a match/mismatch between the developmental and adult diets affects the quantity of fat and glycogen reserves. We found that fat reserves are more sensitive to early life nutritional conditions than 


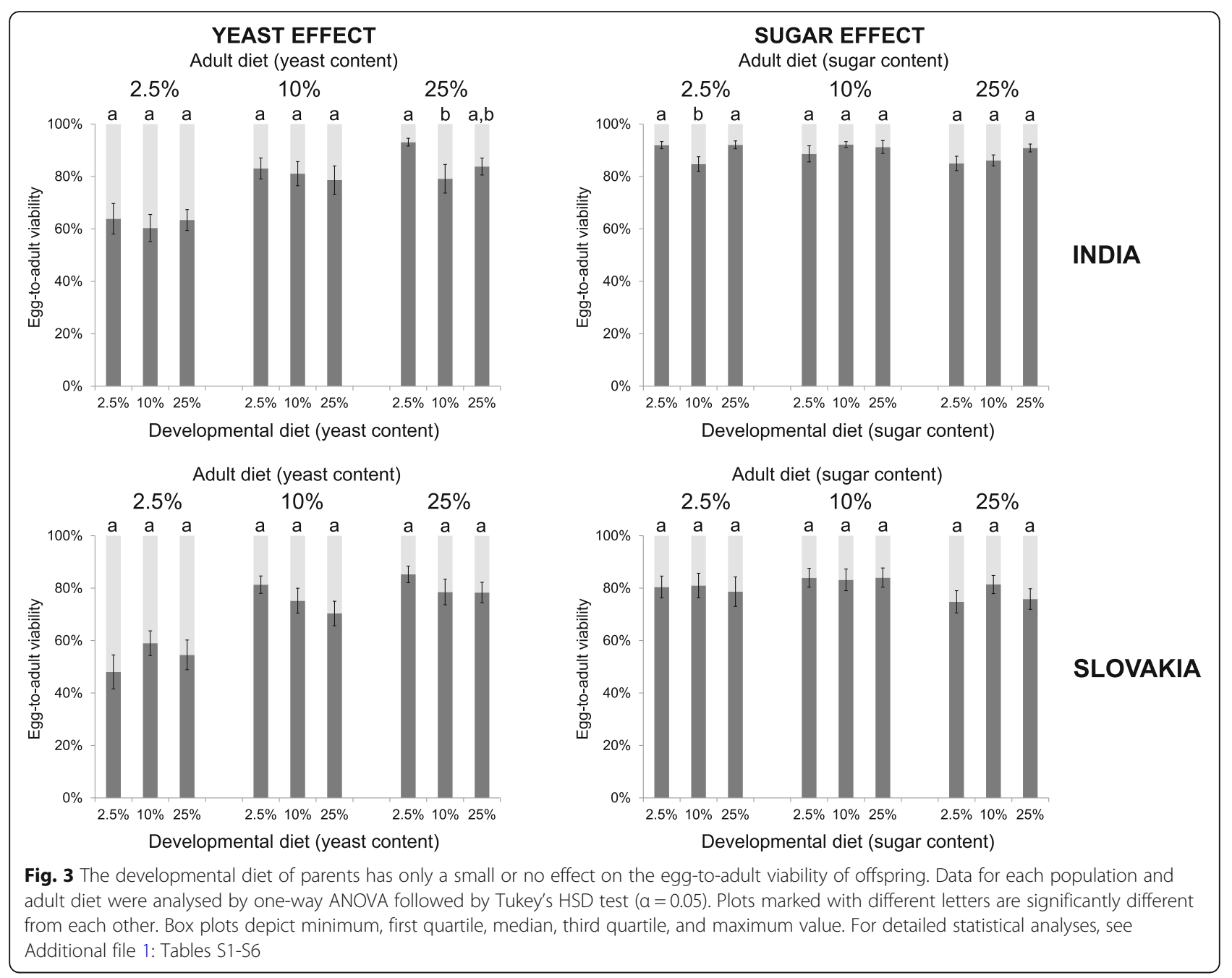

glycogen stores (Figs. 8 and 9; Additional file 1: Table S10). Development on the high-sugar or low-yeast diet significantly increased the fat content at emergence (Fig. 8).

The global statistical analysis showed that the three factors ('population', 'developmental diet' and 'adult diet'), as well as some of their interactions, each have in most cases a significant effect on the fat and glycogen content ten days after emergence (Additional file 1: Tables S11 and S12). However, these effects were more pronounced in the case of fat reserves (Fig. 8) than glycogen reserves (Fig. 9). On diets with varying amounts of yeast, the developmental diet was the most important source of variation in the amount of fat reserves, whereas in the case of diets with varying amounts of sugar, the adult and developmental diet had comparable effects. Altogether, the flies that had developed on the yeast-poor diet had significantly higher fat content irrespective of adult nutrition (Fig. 8). Interestingly, the initially fatter flies that had developed on the high sugar diet had similar amounts of fat stores after ten days as flies that had developed on either intermediate- or low- sugar diet (Fig. 8). This suggests that unlike the lowyeast diet, the effect of the high-sugar developmental diet on body fat content does not persist. For the glycogen contents, we detected only small differences among flies that had developed on different diets (Fig. 9). Most of the variation in the amount of glycogen reserves was attributable primarily to the population origin and then to the adult diet. Importantly, we did not detect any significant effect of a match/mismatch between developmental and adult diets on either fat or glycogen reserves (Additional file 1: Tables S13 and S14).

In general, the adult diet had a similar effect on energy reserves as the developmental diet - the low-yeast and high-sugar diet increased the amount of fat stores. However, the differences in the body fat content among flies fed on the adult diets varying in the sugar content were rather small (Fig. 8). Since this observation was somewhat surprising, we conducted a follow-up experiment, in which we examined how these diets affect body fat content in two standard laboratory strains (Oregon $\mathrm{R}$ and $w^{1118}$ ). This additional experiment revealed that 
YEAST EFFECT
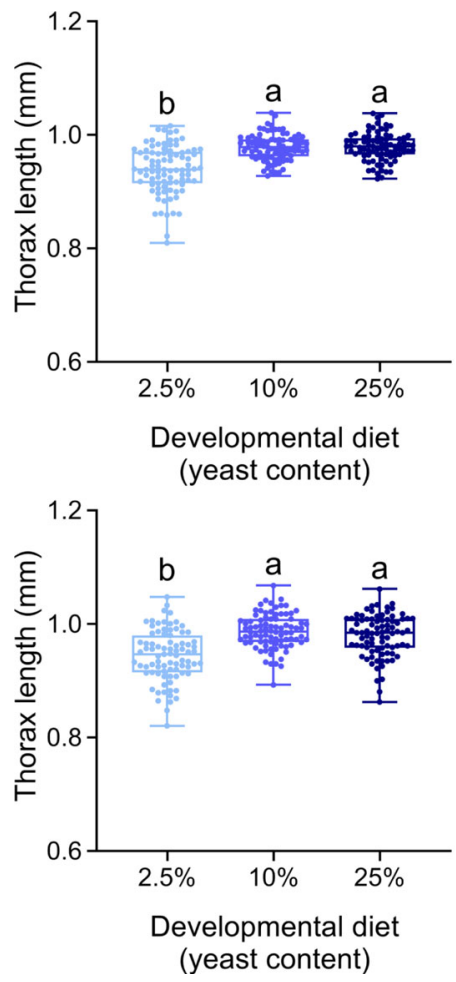

SUGAR EFFECT

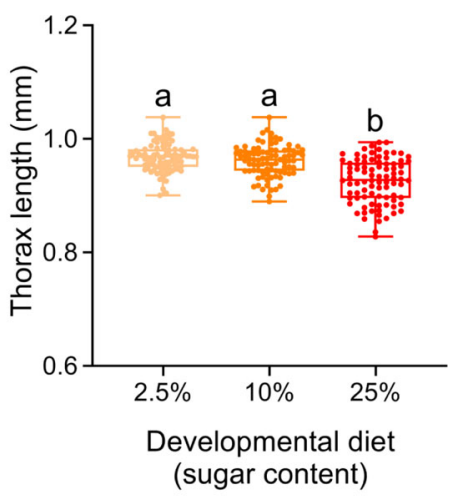

INDIA

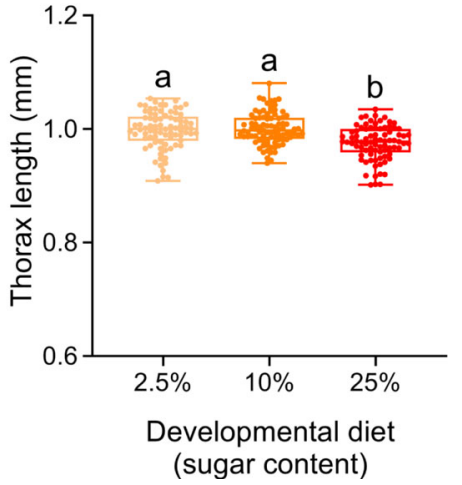

Fig. 4 The yeast and sugar content in the developmental diet has a significant effect on thorax length. Individuals raised on the developmental diet with low (2.5\%) yeast or with high (25\%) sugar contents have reduced thorax length. Data for each population were analysed by one-way ANOVA followed by Tukey's HSD test $(a=0.05)$. Plots marked with different letters are significantly different from each other. Box plots depict minimum, first quartile, median, third quartile, and maximum value. For detailed statistical analyses, see Additional file 1: Table S7

variation in the sugar content of adult diet seems to have a relatively stronger effect on the amount of fat stores in the two laboratory strains than in the outbred wildcaught populations (Additional file 1: Fig. S1). This finding only confirms the previous results on the substantial intraspecific variation in response of lipid reserves to adult dietary sugar [38], and it may also point to a potential effect of inbreeding.

\section{Discussion}

In this study, we tested different competing concepts, which try to explain how the interaction between earlyand late-life nutritional environments affects individual fitness (reviewed in [12]). Based on our experimental data, individuals that had developed either on low-yeast or high-sugar diet had the lowest early reproductive performance. Despite developing in markedly different nutritional environments, both groups of flies shared many phenotypical similarities, such as prolonged development (not shown), smaller body size, fewer ovarioles and increased amount of fat reserves at emergence. Whether all these phenotypes are caused by a single factor (e.g. absolute (low-yeast diet) or relative (high-sugar diet) deficiency of proteins in the developmental diet) or are a result of suboptimal juvenile nutrition in general, may merit closer investigation.

According to the PAR hypothesis, fitness is maximised when the developmental and adult conditions match [7]. Although our results show that a match between developmental and adult diet might have a relatively positive effect on reproductive fitness, individuals that had developed on either low yeast or high sugar diet have lower reproductive fitness across all tested adult nutritional environments. Importantly, their early reproductive performance improved on more favourable adult diets. Overall, we did not find any evidence that individuals that had developed on low yeast or high sugar diet were better adapted to cope with such environments as adults. This finding is consistent with the silver spoon effect, which posits that individuals that developed in optimal conditions always have higher fitness than individuals that developed in a poor environment [13]. The silver spoon effect was also confirmed by other experimental studies that have tested the impact of a match/mismatch between developmental and adult environments on reproductive fitness. For example, Duxbury and Chapman 
YEAST EFFECT
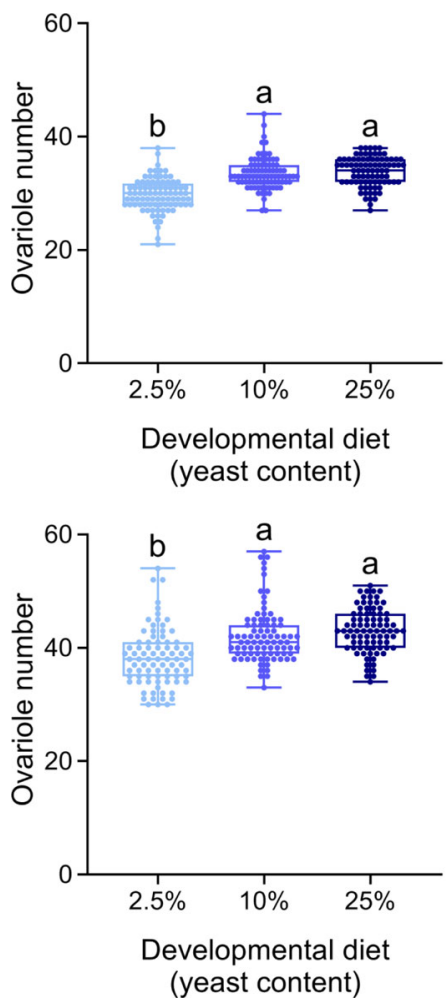

SUGAR EFFECT
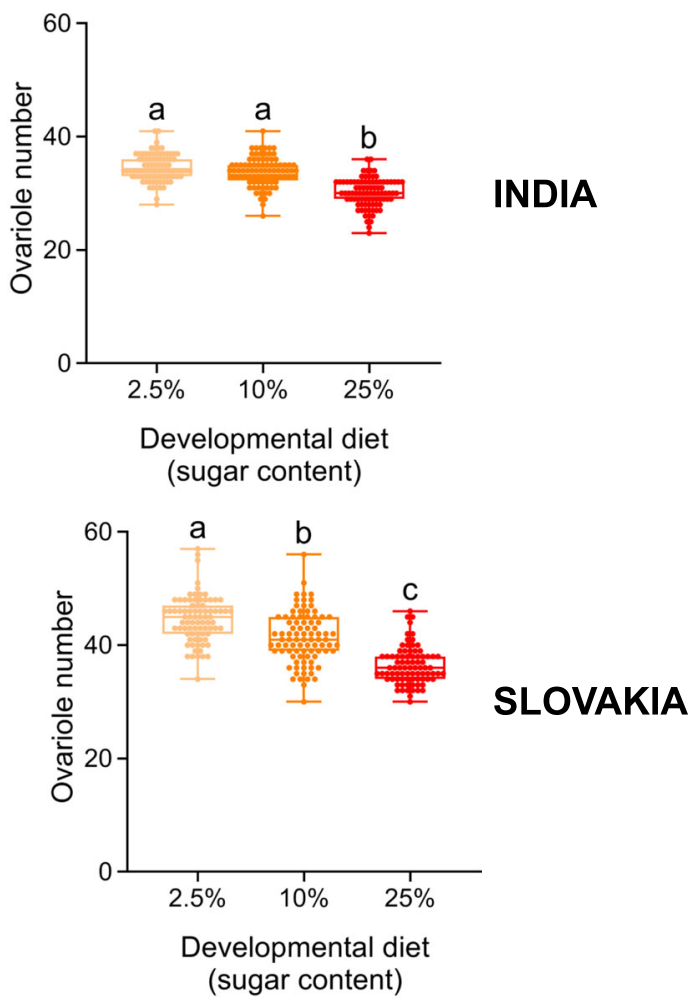

Fig. 5 The yeast and sugar content in the developmental diet has a significant effect on ovariole number. Individuals raised on the developmental diet with low yeast (2.5\%) or with high sugar (25\%) contents have fewer ovarioles. Data for each population were analysed by one-way ANOVA followed by Tukey's HSD test $(a=0.05)$. Plots marked with different letters are significantly different from each other. Box plots depict minimum, first quartile, median, third quartile, and maximum value. For detailed statistical analyses, see Additional file 1: Table S7

[39] showed recently that fecundity of Drosophila is lower in females that have developed on a low-yeast diet. Similarly, May and Zwaan [23] also did not find evidence for the PAR hypothesis when examined Drosophila fecundity and lifespan. In this study, a low-calorie larval diet (low yeast and sugar content) increased both virgin lifespan and early fecundity (measured during the first seven days) irrespective of the adult diet; larval and adult diets had opposite effects on early fecundity. This discrepancy with our results (larval and adult diet have analogous effects on early fecundity) could be explained by the fact that in the study by May and Zwaan [23], yeast and sugar contents were manipulated together, whereas we have tested effects of these two components separately. If larvae are less tolerant to the high sugar concentration (due to glucose toxicity [40]) than adults, negative effects of increased sugar concentration in the larval diet might outweigh positive effects of increased yeast content. However, whether this is indeed the case requires further study.

Studies in other species also provide evidence for the silver spoon effect. For example, Barrett et al. [41] found in the cockroach Nauphoeta cinerea that poor juvenile diet reduced reproductive capacity irrespective of adult conditions. A similar effect has also been documented in the black field cricket Teleogryllus commodus [42], the ladybird beetle Harmonia axyridis [43] and the red flour beetle Tribolium castaneum [44]. In the butterfly Bicyclus anynana, females that experienced food limitation as larvae had lower early reproductive performance in both suboptimal and optimal adult nutritional environment, but only if they were not forced to fly. If they flew for $5 \mathrm{~min}$, their fecundity was comparable to females that developed on an optimal diet [45]. The silver spoon effect might, therefore, be context-dependent (cf. [46]). In contrast, Taborsky [47] found that even though reproductive rate and offspring size in the cichlid fish Simochromis pleurospilus was influenced by juvenile diet, the reproductive success of females depended only on adult diet. Overall, it seems that the majority of experimental studies provide evidence that the developmental diet has indeed the silver spoon effect on reproductive fitness. However, one cannot exclude the possibility that the diet-induced changes might provide other fitness benefits, which cannot be easily assessed in a laboratory environment, e.g. lower energy investment in reproduction 


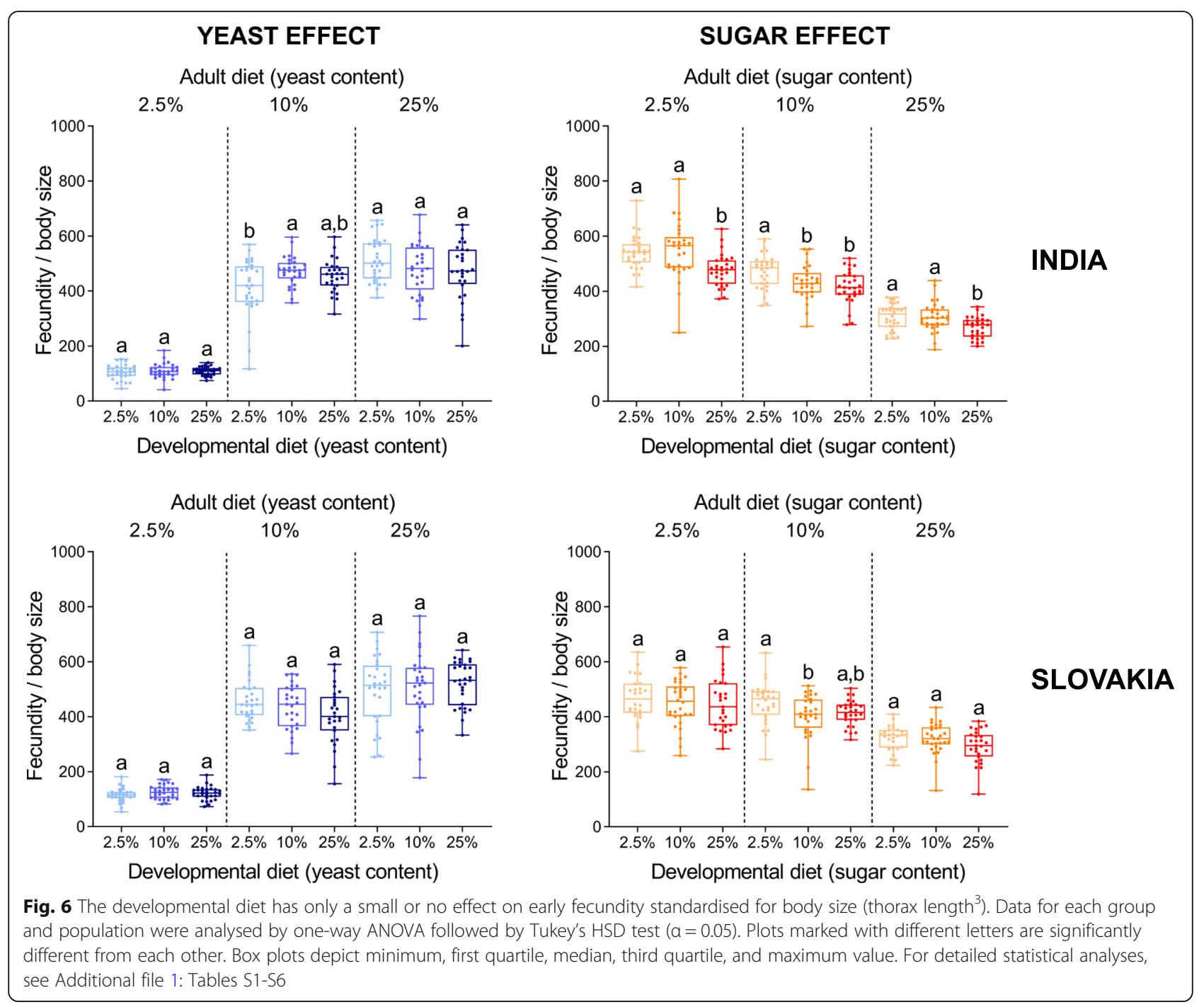

might allow for improved foraging abilities, and thus is adaptive for escaping from poor environments and finding more favourable conditions. Moreover, developmental diet affects also other traits, such as heat, cold, and desiccation resistance, and longevity (e.g. [19, 21, 23, 48]), which we did not examine in our study. It has been shown, for example, that poor-yeast larval diet increases cold resistance [19] and prolongs lifespan [20, 21, 23] in natural environment, these traits might be perhaps more important in terms of individual fitness than early fecundity.

Another reason for not detecting adaptive plasticity might be that the developmental diets that reduced reproductive fitness represent stressful environments [49]. In other words, these nutritional conditions are unfavourable and not in the tolerance zone, but in the socalled 'mitigation zone', in which: "fitness declines as the development of an optimal phenotype is constrained" [12]. However, we presume that decreased reproductive performance on a low-yeast or high-sugar diet might be caused by reduced body size and ovariole number, traits that are positively associated with fecundity $[30,36,50]$. Since these morphological traits change gradually in response to yeast availability (Figs. 4 and 5), it is reasonable to assume that there is an optimal (mainly proteindependent) developmental diet that maximises these two traits, and as a consequence also reproductive output. Of note, the existence of optimal early-life conditions has also been found for another environmental factor - developmental temperature (e.g. $[37,51,52])$.

The necessary condition for the evolution of predictive adaptive responses is that early-life environment carries reliable information about the future adult environment [53]. According to Barrett et al. [41], such condition might be fulfilled in insect species in which juveniles and adults share the same nutritional niche. In contrast, in species in which juveniles and adults differ significantly with regard to their diet, developmental conditions can 


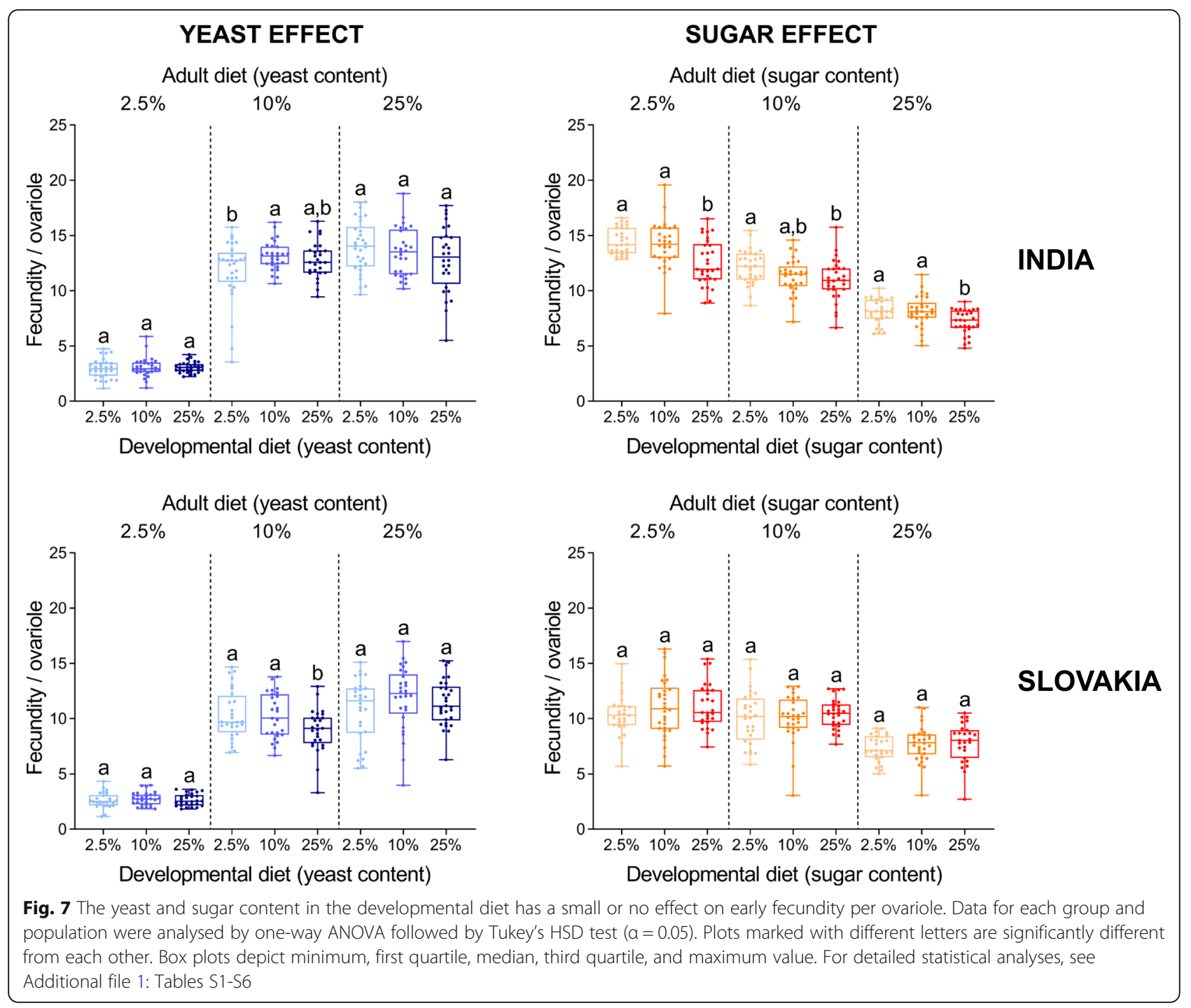

hardly be indicative of adult conditions. Although Drosophila larvae and adults share a common nutritional niche (decaying fruit), it is questionable in this case to what extent can early-life environment provide a reliable clue for future conditions. Moreover, since adult Drosophila has relatively high mobility (its dispersal capacity is approximately $100-200 \mathrm{~m}$ per day [54], a distance that might be sufficient for finding suitable food resources), larval conditions are probably not a relevant indicator of the adult environment in fruit flies.

In holometabolous insects, a large proportion of energy reserves in young adults is accumulated during larval development [55]. Therefore, it is perhaps not surprising that the developmental diet has a significant impact on the amount of Drosophila energy stores at emergence. Specifically, a yeast-poor or sugar-rich larval diet increases the quantity of fat reserves in adults [20, $21,56]$. The inverse relation we observed here between the yeast content in the developmental diet and the amount of fat stored in 10-day old flies seems to support the thrifty phenotype hypothesis, i.e. poor nutritional conditions during early development can lead to increased accumulation of fat later in life [5]. Importantly, the higher fat content in adults that had developed on the low-yeast diet was not caused by increased fat deposition during adulthood (the overall amount of body fat declines with age), but by their larger fat reserves accumulated during the larval stage. As expected, flies that had developed on the high-sugar diet also stored substantially more fat at emergence (this amount was equal or higher than the amount of fat stored by flies that had developed on the low-yeast diet). However, after ten days, their fat content was comparable to flies that had developed on diets containing less sugar. Altogether, the 'obese phenotype' caused by a low-yeast larval diet seems to be more persistent than the one caused by a high- 


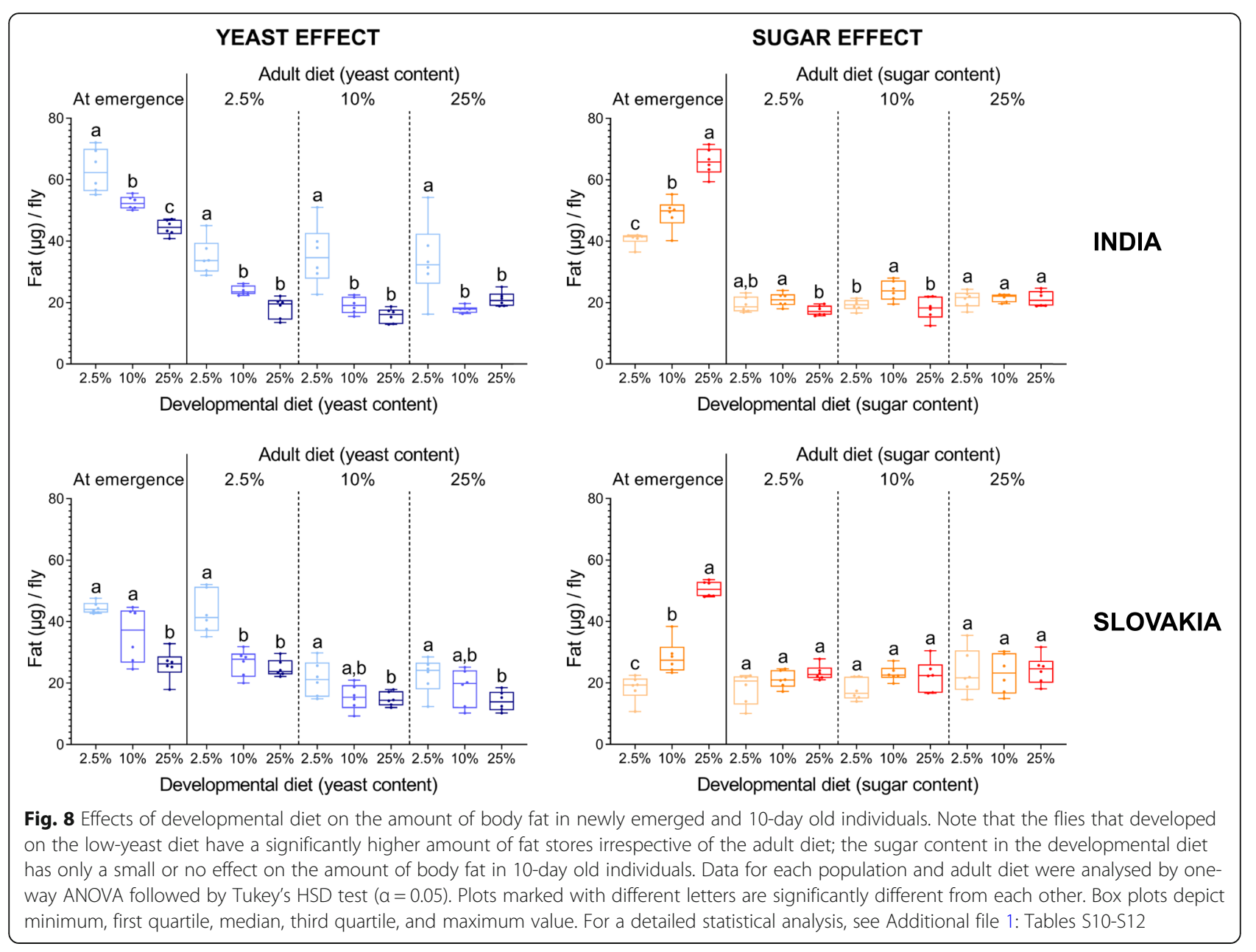

sugar larval diet. However, the underlying cause of this phenomenon is unclear. The increased amount of energy reserves in individuals that experienced poor larval conditions has also been documented in other insect species, such as the moth Spodoptera eridania [57], Manduca sexta [58], or the cockroach Nauphoeta cinerea [41]. The higher fat content in Drosophila individuals reared on a low-yeast diet leads to improved starvation resistance [21] - a quality which can be essential for survival in a nutrition-poor environment. Besides, a higher amount of energy reserves can increase dispersal capacity and allow moving to more favourable conditions [43]. Overall, the increased allocation of limited resources to energy reserves on a poor larval diet might represent a predictive adaptive response to anticipated adverse nutritional conditions in adulthood. On the other hand, undernutrition can potentially induce a fat phenotype also via compensatory feeding. Increased food intake as compensation for the deficiency of a crucial nutrient is a common physiological strategy (reviewed in [59]). In many species, including Drosophila [24] and humans [60], a low-protein diet increases food intake, which in turn leads to elevated energy uptake and promotes fat storage [24, 61]. Thus, although increased energy reserves provide undoubtedly an advantage in a poor nutritional environment, we presume that it is not an adaptive response, but more likely a consequence of compensatory feeding [21].

\section{Conclusions}

The issue whether early developmental diet triggers adaptive phenotypic response is closely related to a more general and debatable question on the character of developmental plasticity (e.g. [62]). Whereas some traits may respond adaptively to environmental factors and stimuli, changes in others might be just inevitable consequences of the altered developmental environment [63]. Our data on the reproductive performance of Drosophila do not provide evidence for an adaptive character of diet-induced phenotypic changes; a match between developmental and adult nutritional conditions did not necessarily maximize reproductive fitness. Regardless of adult nutrition, development on either low-yeast or high-sugar diet negatively affected individual fecundity. 


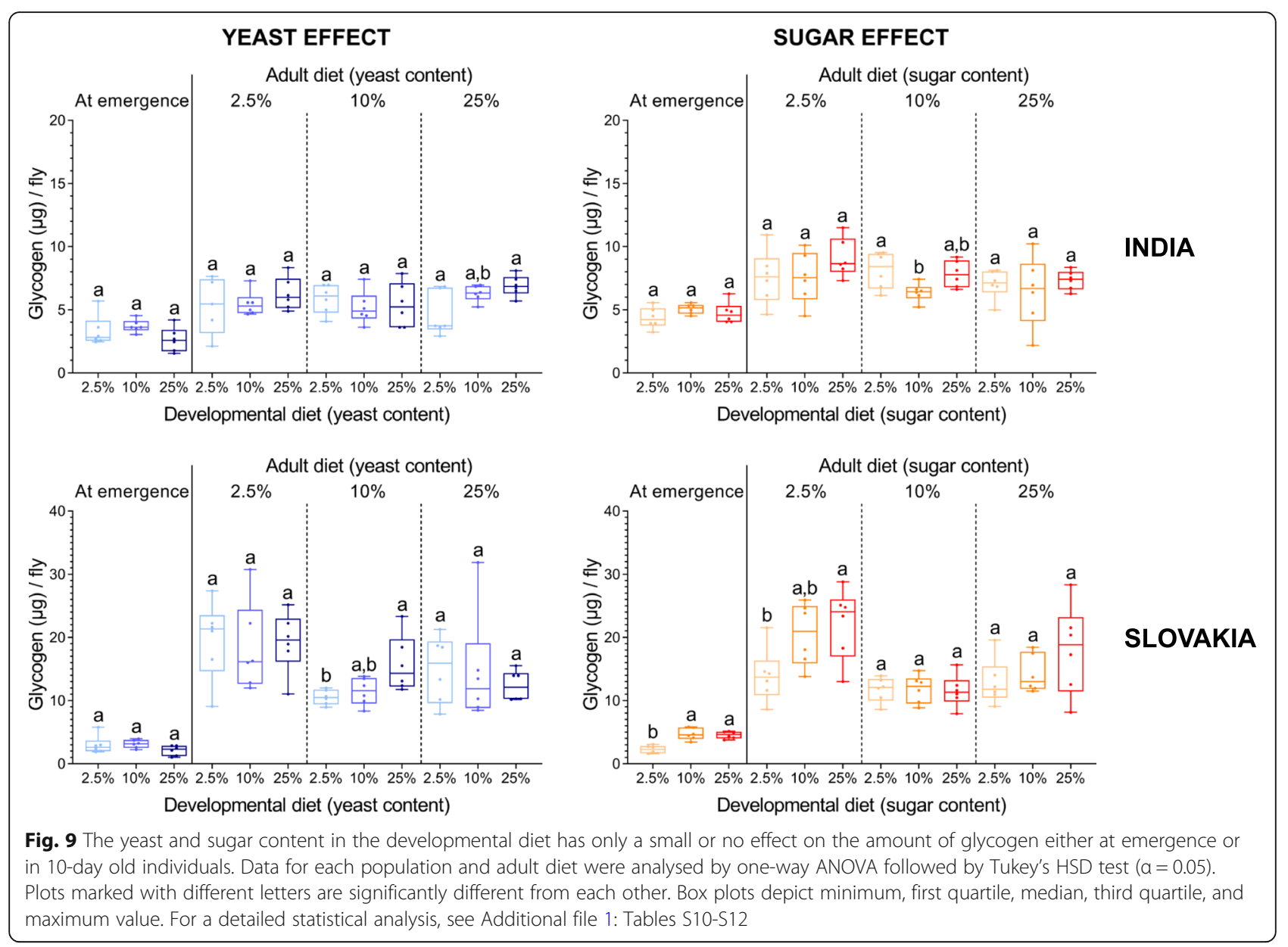

The decreased performance resulted very likely from smaller body size and reduced ovariole number. These findings agree well with the notion of the silver spoon effect, i.e. unfavourable developmental conditions negatively affect fitness-related traits. On the other hand, increased accumulation of lipids during the larval stage in flies that developed on a low-yeast diet can certainly provide a substantial advantage in nutrient-poor conditions. However, whether this represents a predictive adaptive response or it is just a by-product of compensatory feeding as larvae merits further investigation.

\section{Methods}

\section{Fly populations}

We used two outbred wild-caught populations of $D$. melanogaster from (i) Slovakia (Bratislava; collected in October 2017), and (ii) India (Mysore, Karnataka; collected in July (monsoon season) 2017) (for further details see [37]). Both populations were kept in the laboratory as outbred (Indian population for approx. 28 and Slovakian population for approx. 24 generations prior to the experiments) at population sizes of approx. 1500-2000 adults with overlapping generations (generation time approx. 3 weeks). In addition, in a follow-up experiment, we also used two laboratory strains Oregon $\mathrm{R}$ and $w^{1118}$. Prior to the experiments (see below), all flies were maintained on a standard Drosophila medium (6 g agar, $50 \mathrm{~g}$ yeast (instant dry yeast Backaldrin), $50 \mathrm{~g}$ sucrose, $70 \mathrm{~g}$ maize flour, $5.12 \mathrm{ml}$ propionic acid and $1.3 \mathrm{~g}$ methylparaben per $1 \mathrm{l}$ of medium) at $25^{\circ} \mathrm{C}(12 \mathrm{~h}: 12 \mathrm{~h}$ light/dark cycle, $60 \%$ humidity).

\section{Dietary treatments}

The effect of the developmental diet on reproductive performance and the amount of energy reserves was tested by using full factorial design with three 'developmental' and three 'adult' diets (Fig. 1). To examine the effects of major dietary components, yeast and sugar, we carried out two separate experiments. In the first experiment, we used diets with different yeast concentration: low (2.5\%), intermediate (10\%), and high-yeast $(25 \%$ yeast (instant dry yeast Backaldrin)) diet (with 10\% sucrose, $6 \mathrm{~g}$ agar, $5.12 \mathrm{ml}$ propionic acid and $1.3 \mathrm{~g}$ methylparaben per 11 of medium). In the second experiment, we examined the effect of low (2.5\%), intermediate (10\%), and high-sugar (25\% sucrose) diet (with 10\% 
yeast, $6 \mathrm{~g}$ agar, $5.12 \mathrm{ml}$ propionic acid and $1.3 \mathrm{~g}$ methylparaben per 11 of medium) (Fig. 1). The choice of diets is based on the study by Skorupa et al. [24]. All experimental diets are within a range that Drosophila adults can tolerate without substantial reduction in lifespan [24].

\section{Fecundity and viability}

To obtain parental flies for experimental individuals for measuring early reproductive performance, flies from stock populations laid eggs into vials $(68 \mathrm{ml})$ with a standard Drosophila medium $(22 \mathrm{ml})$ for four hours; afterwards, the adult flies were removed, and eggs were used to generate parental populations. Next, we enabled one-week-old parental flies (approx. 100 individuals) to lay eggs into vials with the distinct experimental diets (low, intermediate or high yeast/sugar diet) for four hours. In order to avoid larval crowding, we used an intermediate egg density - approx. 150 eggs per $68 \mathrm{ml}$ vial (containing $22 \mathrm{ml}$ of food); any excessive eggs were removed. Vials with eggs (12 vials per developmental diet per population) were kept at $25^{\circ} \mathrm{C}, 12 \mathrm{~h}: 12 \mathrm{~h}$ light/ dark cycle, and $60 \%$ humidity. All experimental flies were collected within $12 \mathrm{~h}$ after emergence (females were collected as virgins) and randomly placed on three different 'adult' diets (low, intermediate or high yeast/ sugar diet); i.e. for each population and the developmental diet, we established three different 'adult' diet groups (Fig. 1). Each group consisted of 30 females, which were kept individually (in $46 \mathrm{ml}$ vials with $9 \mathrm{ml}$ of food) with two males that developed on the same diet as females (i.e. the female fitness cannot technically be considered independent of paternal effects). All flies were transferred every $24 \mathrm{~h}$ to vials with fresh medium. The number of eggs was counted under a stereomicroscope. Early fecundity was expressed as a cumulative number of eggs laid by a single female during the first ten days [37]. After egg counting, vials with eggs laid on the 10th day were kept to determine the egg-to-adult viability - i.e. the proportion of eclosed flies. After ten days, all females were collected and examined for their thorax length and ovariole number. Data on females that escaped or died during the experiments were excluded from all analyses. At the end of the experiments, males were collected to determine their fat and glycogen content. All experiments were performed at $25^{\circ} \mathrm{C}, 12 \mathrm{~h}: 12 \mathrm{~h}$ light/dark cycle, and $60 \%$ humidity.

\section{Morphological traits}

Thorax length was measured and the number of ovarioles determined as described in detail in [37]. Both morphological traits were measured in 10-day old females (i.e. 27-30 individuals per treatment per population), which were used in the fecundity and egg-to-adult viability assays (see the previous section Fecundity and viability). As a proxy for body size, we used the cubed thorax length (thorax length ${ }^{3}$ ) [37, 64]. Ovariole number is expressed as the sum of ovarioles from both ovaries.

\section{Fat and glycogen quantification}

Energy reserves were quantified in newly emerged and 10day old males (5-6 replicates per treatment per population; 5 males per replicate), which were used in the fecundity and egg-to-adult viability assays (see the section Fecundity and viability). Energy reserves were measured only in male flies, because, in females, a considerable proportion of triglycerides (fat) [65] and glycogen [66, 67] is allocated to the growing oocytes. Fat and glycogen content were determined using standard protocols based on the colourimetric assays [68]. Both types of energy reserves were measured from the same starting homogenates, prepared as described in detail in [69]. Lipids were quantified using the Triglycerides kit (Randox, TR1697). Glycogen levels were analysed by glucose oxidation kit (Sigma, GAGO20) after digestion by $\alpha$-amyloglucosidase (Sigma A1602), as described previously [68].

In a follow-up experiment, we measured fat content in males (including the two laboratory strains - Oregon- $\mathrm{R}$ and $w^{1118}$ ) that had developed on the intermediate sugar diet ( $10 \%$ sucrose). After emergence, they were transferred together with females (30 males and 30 females per vial/ replicate; 3 replicates per adult diet) either to low (5\%), intermediate (10\%), or high ( $25 \%$ sucrose) sugar diet with daily food exchange. After ten days, all males were collected (5-6 replicates per treatment per population/strain; 5 males per replicate), and their lipid content quantified as described above.

\section{Statistical analysis}

We performed a global analysis of individual fitnessrelated traits (early fecundity, viability, early fecundity standardised for body size, early fecundity per ovariole number, fat and glycogen content) by using full factorial, multi-way analysis of variance (ANOVA, type III sum of squares) with population, developmental and adult diet as fixed effects, and their interactions. To examine the effect of population and the developmental diet on a given trait at different adult diets, we used full factorial, two-way fixed-effects ANOVA with interaction. To test the effect of the developmental diet on a given trait at different adult nutrition and separately for each population, we performed one-way ANOVA with Tukey's Honest Significant Difference (HSD) posthoc test with $\alpha=$ 0.05 . Thorax length and ovariole number were analysed by using two-way ANOVA with two fixed factors, population and the developmental diet, and their interaction, and also separately for each population by one-way ANOVA with the developmental diet as a fixed factor with Tukey's HSD posthoc test $(\alpha=0.05)$. To control for 
differences in body size and ovariole number, we used the same approach as described in [37]. In addition to analysing fecundity standardised for body size (thorax length ${ }^{3}$ ) and fecundity per ovariole, we performed for each population and adult diet analysis of covariance (ANCOVA), with the developmental diet as the fixed factor and thorax length or ovariole number as the covariate, followed by Tukey's HSD posthoc test $(\alpha=0.05)$. Finally, to test whether a match vs mismatch between developmental and adult diet affects a given trait, first, we examined the residuals from the ANOVA (using all factors - population, developmental and adult diet) dependent on the degree of mismatch (similar = 0 [larval 2.5\% (either yeast or sugar) and adult 2.5\%, larval $10 \%$ and adult $10 \%$, larval $25 \%$ and adult $25 \%$ ], one step dissimilar $=1$ [e.g. larval $2.5 \%$ and adult $10 \%$, larval $10 \%$ and adult $25 \%$ etc.], two steps dissimilar $=2$ [e.g. larval $2.5 \%$ and adult $25 \%$ and larval $25 \%$ and adult $2.5 \%$. If the residuals of the model were highest for 0 , intermediate for 1 and lowest for 2 , this would indicate that a match between nutritional environments has a positive effect on a given trait. Next, we fitted the degree of mismatch $(0,1,2)$ in the ANOVA model with all factors (population, developmental diet, adult diet, and mismatch).

All analyses were performed using JMP 15 (SAS Institute, Cary, NC, USA) and PAST 3.11 software [70]; graphs were created in Graphpad Prism 8 (GraphPad Software Inc.) and Excel (Microsoft).

\section{Supplementary information}

Supplementary information accompanies this paper at https://doi.org/10. 1186/s12862-020-01663-y.

Additional file 1: Fig. S1. Intraspecific variation in the effect of sugar in the adult diet on the amount of fat in 10 day-old males. Table S1. The results of ANOVA for the effect of population, the yeast content in the developmental and the adult diet, and their interactions on early fecundity, egg-to-adult viability, early fecundity standardised for body size, and early fecundity per ovariole. Table S2. The results of ANOVA for the effect of population, the sugar content in the developmental and adult diet, and their interactions on early fecundity, egg-to-adult viability, early fecundity standardised for body size, and early fecundity per ovariole. Table S3. The results of ANOVA for the effect of population, the yeast content in the developmental and the adult diet, and a match/mismatch between developmental and adult nutritional environment on early fecundity, egg-to-adult viability, early fecundity standardised for body size, and early fecundity per ovariole. Table S4. The results of ANOVA for the effect of population, the sugar content in the developmental and the adult diet, and a match/mismatch between developmental and adult nutritional environment on early fecundity, egg-to-adult viability, early fecundity standardised for body size, and early fecundity per ovariole. Table S5. The results of ANOVA for the effect of population and the yeast content in the developmental diet, and their interactions on various traits on different adult diets. Table S6. The results of ANOVA for the effect of population and the sugar content in the developmental diet, and their interactions on various traits on different adult diets. Table S7. The results of ANOVA for the effect of population and the yeast or sugar content in the developmental diet, and their interactions on thorax length and ovariole number. Table S8. The ANCOVA results for early fecundity with the yeast content in the developmental diet as the fixed factor and thorax length or ovariole number as the covariate. Table S9. The ANCOVA results for early fecundity with the sugar content in the developmental diet as the fixed factor and thorax length or ovariole number as the covariate. Table S10. The results of ANOVA for the effect of population and the yeast or sugar content in the developmental diet, and their interactions on the fat and glycogen content at emergence. Table S11. The results of ANOVA for the effect of population, the yeast content in the developmental and the adult diet, and their interactions on the fat content and glycogen content in 10-day old males. Table S12. The results of ANOVA for the effect of population, the sugar content in the developmental and the adult diet, and their interactions on fat content and glycogen content in 10-day old males. Table S13. The results of ANOVA for the effect of population, the yeast content in the developmental and the adult diet, and a match/mismatch between developmental and adult nutritional environment on fat content and glycogen content in 10-day old males. Table S14. The results of ANOVA for the effect of population, the sugar content in the developmental and the adult diet, and a match/mismatch between developmental and adult nutritional environment on fat content and glycogen content in 10-day old males.

Additional file 2. Data. Data generated and analysed during this study.

\section{Abbreviations}

ANCOVA: Analysis of covariance; ANOVA: Analysis of variance; PAR: Predictive adaptive response; Tukey's HSD test: Tukey's honest significant difference test

\section{Acknowledgements}

We are grateful to Dr. L'ubomír Vidlička for the wild-caught flies from Slovakia and to Prof. Ravi Parkash and Dr. B. E. Pradeep for helping us obtaining the flies from India.

\section{Authors' contributions}

PK conceived the study; PK and MG designed the experiments; PK, DK, MG performed the experiments; PK, TNG, HD and MG analysed and interpreted the data; all authors wrote and reviewed the manuscript. The author(s) read and approved the final manuscript.

\section{Funding}

This work was supported by the Slovak Academy of Sciences [MVTS-1219] and VEGA [2/0141/20]. The funding bodies played no role in the design of the study and collection, analysis, and interpretation of data and in writing the manuscript.

\section{Availability of data and materials}

All data generated and analysed during this study are included in this article and its supplementary information files.

Ethics approval and consent to participate

Not applicable.

\section{Consent for publication}

Not applicable.

\section{Competing interests}

The authors declare that they have no competing interests.

\section{Author details}

${ }^{1}$ Institute of Zoology, Slovak Academy of Sciences, Dúbravská cesta 9, 84506 Bratislava, Slovakia. ${ }^{2}$ Department of Genetics, Faculty of Natural Sciences, Comenius University, Ilkovičova 6, Mlynská dolina, 84215 Bratislava, Slovakia. ${ }^{3}$ Department of Biosciences, Sri Sathya Sai Institute of Higher Learning, Prasanthi Nilayam 515134, India. ${ }^{4}$ Department of Zoology, Stockholm University, Svante Arrhenius väg 18B, S-106 91 Stockholm, Sweden.

Received: 16 February 2020 Accepted: 23 July 2020

Published online: 29 July 2020

\section{References}

1. Canani RB, Costanzo MD, Leone L, Bedogni G, Brambilla P, Cianfarani S, Nobili V, Pietrobelli A, Agostoni C. Epigenetic mechanisms elicited by nutrition in early life. Nutr Res Rev. 2011;24:198-205. https://doi.org/10.1017/ S0954422411000102. 
2. Reynolds CM, Gray C, Li M, Segovia SA, Vickers MH. Early life nutrition and energy balance disorders in offspring in later life. Nutrients. 2015;7:8090111. https://doi.org/10.3390/nu7095384.

3. Hoffman DJ, Reynolds RM, Hardy DB. Developmental origins of health and disease: current knowledge and potential mechanisms. Nutr Rev. 2017;75: 951-70. https://doi.org/10.1093/nutrit/nux053.

4. Hales CN, Desai M, Ozanne SE. The thrifty phenotype hypothesis: how does it look after 5 years? Diabet Med. 1997;14:189-95. https://doi.org/10.1002/ (SICI)1096-9136(199703)14:3<189::AID-DIA325>3.0.CO;2-3.

5. Hales CN, Barker DJ. The thrifty phenotype hypothesis. Br Med Bull. 2001;60: 5-20. https://doi.org/10.1093/bmb/60.1.5.

6. Williams L, Seki Y, Vuguin PM, Charron MJ. Animal models of in utero exposure to a high fat diet: a review. Biochim Biophys Acta. 1842;2014:50719. https://doi.org/10.1016/j.bbadis.2013.07.006

7. Gluckman PD, Hanson MA. The developmental origins of the metabolic syndrome. Trends Endocrinol Metab. 2004;15:183-7. https://doi.org/10.1016/ j.tem.2004.03.002.

8. Bateson P, Gluckman P, Hanson M. The biology of developmental plasticity and the predictive adaptive response hypothesis. J Physiol. 2014;592:235768. https://doi.org/10.1113/jphysiol.2014.271460.

9. Nettle D, Bateson M. Adaptive developmental plasticity: what is it, how can we recognize it and when can it evolve? Proc Biol Sci. 2015;282:20151005. https://doi.org/10.1098/rspb.2015.1005.

10. Nettle D, Frankenhuis WE, Rickard IJ. The evolution of predictive adaptive responses in human life history. Proc Biol Sci. 2013;280:20131343. https:// doi.org/10.1098/rspb.2013.1343.

11. van den Heuvel J, Saastamoinen M, Brakefield PM, Kirkwood TBL, Zwaan BJ, Shanley DP. The predictive adaptive response: modeling the life-history evolution of the butterfly Bicyclus anynana in seasonal environments. Am Nat. 2013;181:E28-42. https://doi.org/10.1086/668818.

12. Monaghan P. Early growth conditions, phenotypic development and environmental change. Philos trans R Soc Lond B bio. Sci. 2008;363:1635-45. https://doi.org/10.1098/rstb.2007.0011

13. Grafen A. 1988 on the uses of data on lifetime reproductive success. In: Clutton-Brock T, editor. Reproductive success. Chicago, IL: University of Chicago Press; 1988. p. 454-71.

14. Baker KD, Thummel CS. Diabetic larvae and obese flies - emerging studies of metabolism in Drosophila. Cell Metab. 2007;6:257-66. https://doi.org/10. 1016/j.cmet.2007.09.002.

15. Gáliková M, Klepsatel P. Obesity and aging in the Drosophila model. Int J Mol Sci. 2018;19:E1896. https://doi.org/10.3390/ijms19071896.

16. De Moed GH, De Jong G, Scharloo W. Environmental effects on body size variation in Drosophila melanogaster and its cellular basis. Genet Res. 1997; 70:35-43. https://doi.org/10.1017/s0016672397002930.

17. Tu MP, Tatar M. Juvenile diet restriction and the aging and reproduction of adult Drosophila melanogaster. Aging Cell. 2003;2:327-33. https://doi.org/10. 1046/j.1474-9728.2003.00064.x.

18. Jang T, Lee KP. Comparing the impacts of macronutrients on life-history traits in larval and adult Drosophila melanogaster: the use of nutritional geometry and chemically defined diets. J Exp Biol. 2018;221: jeb181115. doi: https://doi.org/10.1242/jeb.181115.

19. Henry Y, Overgaard J, Colinet H. Dietary nutrient balance shapes phenotypic traits of Drosophila melanogaster in interaction with gut microbiota. Comp Biochem Physiol A Mol Integr Physiol. 2019;29:241:110626. doi: https://doi. org/10.1016/j.cbpa.2019.110626

20. Stefana MI, Driscoll PC, Obata F, Pengelly AR, Newell CL, MacRae Jl, et al. Developmental diet regulates Drosophila lifespan via lipid autotoxins. Nat Commun. 2017:8:1384. https://doi.org/10.1038/s41467-017-01740-9.

21. Klepsatel P, Procházka E, Gáliková M. Crowding of Drosophila larvae affects lifespan and other life-history traits via reduced availability of dietary yeast. Exp Gerontol. 2018:110:298-308. https://doi.org/10.1016/j.exger.2018.06.016.

22. Osborne AJ, Dearden PK. A 'phenotypic hangover': the predictive adaptive response and multigenerational effects of altered nutrition on the transcriptome of Drosophila melanogaster. Environ Epigenet. 2017;3(4): dvx019. doi: https://doi.org/10.1093/eep/dvx019.

23. May CM, Zwaan BJ. Relating past and present diet to phenotypic and transcriptomic variation in the fruit fly. BMC Genomics. 2017;18:640. https:// doi.org/10.1186/s12864-017-3968-z.

24. Skorupa DA, Dervisefendic A, Zwiener J, Pletcher SD. Dietary composition specifies consumption, obesity, and lifespan in Drosophila melanogaster. Aging Cell. 2008;7:478-90. https://doi.org/10.1111/j.1474-9726.2008.00400.x.
25. Bos M, Burnet B, Farrow R, Woods RA. Development of Drosophila on sterol mutants of the yeast Saccharomyces cerevisiae. Genet Res. 1976:163-76. https://doi.org/10.1017/S0016672300016840.

26. Lüersen K, Röder T, Rimbach G. Drosophila melanogaster in nutrition research-the importance of standardizing experimental diets. Genes Nutr. 2019;14:3. https://doi.org/10.1186/s12263-019-0627-9.

27. Rodrigues MA, Martins NE, Balancé LF, Broom LN, Dias AJS, Fernandes ASD, Rodrigues F, Sucena E, Mirth CK. Drosophila melanogaster larvae make nutritional choices that minimize developmental time. J Insect Physiol. 2015; 81:69-80. https://doi.org/10.1016/j.jinsphys.2015.07.002.

28. Jang T, Lee KP. Comparing the impacts of macronutrients on life-history traits in larval and adult Drosophila melanogaster: the use of nutritional geometry and chemically defined diets. J Exp Biol. 2018; 221(Pt 21): jeb181115. doi: https://doi.org/10.1242/jeb.181115.

29. Rosewell J, Shorrocks B. The implication of survival rates in natural populations of Drosophila: capture-recapture experiments on domestic species. Biol J Linn Soc. 1987;32:373-84. https://doi.org/10.1111/j.1095-8312. 1987.tb00438.x.

30. Klepsatel P, Gáliková M, De Maio N, Ricci S, Schlötterer C, Flatt T. Reproductive and post-reproductive life history of wild-caught Drosophila melanogaster under laboratory conditions. J Evol Biol. 2013;26:1508-20. https://doi.org/10.1111/jeb.12155.

31. Rion S, Kawecki TJ. Evolutionary biology of starvation resistance: what we have learned from Drosophila. J Evolution Biol. 2007;20:1655-64. https://doi. org/10.1111/j.1420-9101.2007.01405.x.

32. Hughes KA. The inbreeding decline and average dominance of genes affecting male life-history characters in Drosophila melanogaster. Genet Res. 1995:65:41-52. https://doi.org/10.1017/s0016672300032997.

33. Swindell WR, Bouzat JL. Selection and inbreeding depression: effects of inbreeding rate and inbreeding environment. Evolution. 2006;60:1014-22. https://doi.org/10.1554/05-493.1.

34. Robertson FW. Studies in quantitative inheritance XI. Genetic and environmental correlation between body size and egg production in Drosophila melanogaster. J Genet. 1957:55:428.

35. Tantawy AO, Rakha FA. 1964 studies on natural populations of Drosophila. IV. Genetic variances of and correlations between four characters in D. melanogaster and D. simulans. Genetics. 1964;50:1349-55.

36. David JR. Le nombre d'ovarioles chez Drosophila melanogaster: relation avec la fécondité et valeur adaptive. Arch Zool Exp Gen. 1970;111:357-70.

37. Klepsatel P, Girish TN, Dircksen H, Gáliková M. Reproductive fitness of Drosophila is maximised by optimal developmental temperature. J Exp Biol. 2019;20: jeb202184. doi: https://doi.org/10.1242/jeb.202184.

38. Jehrke L, Stewart FA, Droste A, Beller M. The impact of genome variation and diet on the metabolic phenotype and microbiome composition of Drosophila melanogaster. Sci Rep. 2018;8:6215. https://doi.org/10.1038/ s41598-018-24542-5.

39. Duxbury EML, Chapman T. Sex-specific responses of life span and fitness to variation in developmental versus adult diets in Drosophila melanogaster. J Gerontol A Biol Sci Med Sci. 2019. https://doi.org/10.1093/gerona/glz175.

40. Musselman LP, Fink $J$, Baranski TJ. Similar effects of high-fructose and highglucose feeding in a Drosophila model of obesity and diabetes. PLoS One. 2019;14:e0217096. https://doi.org/10.1371/journal.pone.0217096.

41. Barrett EL, Hunt J, Moore AJ, Moore PJ. Separate and combined effects of nutrition during juvenile and sexual development on female life-history trajectories: the thrifty phenotype in a cockroach. Proc Biol Sci. 2009:276: 3257-64. https://doi.org/10.1098/rspb.2009.0725.

42. Zajitschek F, Hunt J, Jennions MD, Hall MD, Brooks RC. Effects of juvenile and adult diet on ageing and reproductive effort of male and female black field crickets Teleogryllus commodus. Funct Ecol. 2008;23:602-11. https://doi. org/10.1111/j.1365-2435.2008.01520.x.

43. Dmitriew $C$, Rowe $L$. Effects of early resource limitation and compensatory growth on lifetime fitness in the ladybird beetle (Harmonia axyridis). J Evo Biol. 2006;20:1298-310. https://doi.org/10.1111/j.1420-9101.2007.01349.x.

44. Plesnar-Bielak A, Woch KR, Małszycki MA, Alkhawlany ATH, Hołysz A, Assis Correia JF, et al. Larval and adult nutrition effects on reproductive traits in the red flour beetle. J Zool. 2017;302:79-87. https://doi.org/10.1111/jzo. 12440 .

45. Saastamoinen $M$, van der Sterren D, Vastenhout N, Zwaan BJ, Brakefield PM. Predictive adaptive responses: condition-dependent impact of adult nutrition and flight in the tropical butterfly Bicyclus anynana. Am Nat. 2010; 176:686-98. https://doi.org/10.1086/657038. 
46. Hopwood PE, Moore AJ, Royle NJ. Effects of resource variation during early life and adult social environment on contest outcomes in burying beetles: a context-dependent silver spoon strategy? Proc Biol Sci. 2014;281:20133102. https://doi.org/10.1098/rspb.2013.3102.

47. Taborsky B. The influence of juvenile and adult environments on life-history trajectories. Proc Biol Sci. 2006;273:741-50. https://doi.org/10.1098/rspb.2005. 3347.

48. Andersen LH, Kristensen TN, Loeschcke V, Toft S, Mayntz D. Protein and carbohydrate composition of larval food affects tolerance to thermal stress and desiccation in adult Drosophila melanogaster. J Insect Physiol. 2010;56: 336-40. https://doi.org/10.1016/j.jinsphys.2009.11.006.

49. Woods HA, Harrison JF. Interpreting rejections of the beneficial acclimation hypothesis: when is physiological plasticity adaptive? Evolution. 2002;56: 1863-6. https://doi.org/10.1554/0014-3820(2002)056[1863:IROTBA]2.0.CO;2.

50. Honěk A. Intraspecific variation in body size and fecundity in insects: a general relationship. Oikos. 1993;66:483-92. https://doi.org/10.2307/3544943.

51. Zwaan BJ, Bijlsma R, Hoekstra RF. On the developmental theory of ageing. II. The effect of developmental temperature on longevity in relation to adult body size in D. melanogaster. Heredity. 1992;68:123-30. https://doi.org/10. 1038/hdy.1992.19.

52. Gibert P, Huey RB, Gilchrist GW. Locomotor performance of Drosophila melanogaster: interactions among developmental and adult temperatures, age, and geography. Evolution. 2001;55:205-9. https://doi.org/10.1111/j. 0014-3820.2001.tb01286.x.

53. Frankenhuis WE, Nettle D, Dall SRX. A case for environmental statistics of early-life effects. Philos Trans R Soc Lond Ser B Biol Sci. 2019;374:20180110. https://doi.org/10.1098/rstb.2018.0110.

54. Mclnnis DO, Schaffer HE, Mettler LE. Field dispersal and population sizes of native Drosophila from North Carolina. Am Nat. 1982;119:319-30. https://doi. org/10.1086/283912.

55. Aguila JR, Hoshizaki DK, Gibbs AG. Contribution of larval nutrition to adult reproduction in Drosophila melanogaster. J Exp Biol. 2013;216:399-406. https://doi.org/10.1242/jeb.078311.

56. Matzkin LM, Johnson S, Paight C, Bozinovic G, Markow TA. Dietary protein and sugar differentially affect development and metabolic pools in ecologically diverse Drosophila. J Nutr. 2011;141:1127-33. https://doi.org/10. 3945/jn.111.138438.

57. Karowe DN, Martin MM. The effects of quantity and quality of diet nitrogen on the growth, efficiency of food utilization, nitrogen budget, and metabolic rate of fifth-instar Spodoptera eridania larvae (Lepidoptera: Noctuidae). J Insect Physiol. 1989;35:699-708. https://doi.org/10.1016/00221910(89)90089-9.

58. Ojeda-Avila T, Woods HA, Raguso RA. Effects of dietary variation on growth, composition, and maturation of Manduca sexta (Sphingidae: Lepidoptera). J Insect Physiol. 2003;49:293-306. https://doi.org/10.1016/s00221910(03)00003-9.

59. Nestel D, Papadopoulos NT, Pascacio-Villafán C, Righini N, Altuzar-Molina AR, Aluja M. Resource allocation and compensation during development in holometabolous insects. J Insect Physiol. 2016;95:78-88. https://doi.org/10. 1016/j.jinsphys.2016.09.010

60. Morrison CD, Laeger T. Protein-dependent regulation of feeding and metabolism. Trends Endocrinol Metab. 2015;26:256-62. https://doi.org/10. 1016/j.tem.2015.02.008

61. Simpson SJ, Raubenheimer D. Obesity: the protein leverage hypothesis. Obes Rev. 2005;6:133-42. https://doi.org/10.1111/j.1467-789X.2005.00178.x.

62. Ghalambor CK, McKay JK, Carroll SP, Reznick DN. Adaptive versus nonadaptive phenotypic plasticity and the potential for contemporary adaptation in new environments. Funct Ecol. 2007;21:394-407. https://doi. org/10.1111/j.1365-2435.2007.01283.x.

63. Stearns SC. The evolutionary significance of phenotypic plasticity. Phenotypic sources of variation among organisms can be described by developmental switches and reaction norms. BioScience. 1989;39:436-45. https://doi.org/10.2307/1311135.

64. Klepsatel P, Gáliková M, Huber CD, Flatt T. Similarities and differences in altitudinal versus latitudinal variation for morphological traits in Drosophila melanogaster. Evolution. 2014;68:1385-98. https://doi.org/10.1111/evo.12351.

65. Sieber MH, Spradling AC. Steroid signaling establishes a female metabolic state and regulates SREBP to control oocyte lipid accumulation. Curr Biol. 2015;25:993-1004. https://doi.org/10.1016/j.cub.2015.02.019.

66. Tennessen JM, Bertagnolli NM, Evans J, Sieber MH, Cox J, Thummel CS. Coordinated metabolic transitions during Drosophila embryogenesis and the onset of aerobic glycolysis. G3 (Bethesda). 2014;4:839-50. doi: https:// doi.org/10.1534/g3.114.010652.

67. Yamada T, Habara O, Yoshii Y, Matsushita R, Kubo H, Nojima Y, et al. The role of glycogen in development and adult fitness in Drosophila. Development. 2019;146: dev176149. doi: https://doi.org/10.1242/dev.176149.

68. Tennessen JM, Barry WE, Cox J, Thummel CS. Methods for studying metabolism in Drosophila. Methods. 2014;68:105-15. https://doi.org/10.1016/ j.ymeth.2014.02.034.

69. Gáliková M, Klepsatel P, Münch J, Kühnlein RP. Spastic paraplegia-linked phospholipase PAPLA1 is necessary for development, reproduction, and energy metabolism in Drosophila. Sci Rep. 2017;7:46516. https://doi.org/10 1038/srep46516.

70. Hammer $\varnothing$, Harper DAT, Ryan PD. Past: paleontological statistics software package for education and data analysis. Palaeontol Electron. 2001:4:4 http://palaeo-electronica.org/2001_1/past/issue1_01.htm.

\section{Publisher's Note}

Springer Nature remains neutral with regard to jurisdictional claims in published maps and institutional affiliations.
Ready to submit your research? Choose BMC and benefit from:

- fast, convenient online submission

- thorough peer review by experienced researchers in your field

- rapid publication on acceptance

- support for research data, including large and complex data types

- gold Open Access which fosters wider collaboration and increased citations

- maximum visibility for your research: over $100 \mathrm{M}$ website views per year

At BMC, research is always in progress.

Learn more biomedcentral.com/submissions 